\title{
IDENTIDADES Y POLÍTICA EN LA ERA DE LOS FUNDAMENTALISMOS
}

\section{IDENTITIES AND POLITICS IN THE ERA OF THE FUNDAMENTALISMS}

\author{
Patricia Alvarenga Venutolo \\ patricia.alvarenga.venutolo@una.cr \\ Universidad Nacional, Costa Rica
}

Recibido: 20 de julio de 2018 • Aceptado: 30 de julio de 2018 Publicado: 9 de octubre de 2018

\begin{abstract}
Resumen
Con el fin de contribuir a la discusión sobre la pasada ronda electoral en febrero de 2018 en Costa Rica, el presente artículo acude a teóricos de la política, como Norbert Lechner, Ernesto Laclau y Chantal Mauffe. Este se propone explicar por qué la instauración de verdades inconmovibles en la esfera pública atenta directamente contra las dinámicas propias de lo político. Pero, a la vez, propone ubicar en el análisis teórico cómo en el juego político entran en disputa dinámicas culturales contradictorias que alimentan las subjetividades políticas. Reflexiona acerca de los riesgos que actualmente corren los significativos triunfos de los movimientos en torno a la sexualidad, ante la embestida del fundamentalismo religioso a la cultura de la tolerancia. El artículo también se propone ubicar el caso costarricense en dinámicas propias de lo que podríamos llamar la globalización cultural, la cual hoy tiende hacia el desprecio de la agenda que se ha venido construyendo en torno a los derechos humanos, a partir de la Segunda Guerra Mundial. Se ofrecen reflexiones comparativas con Nicaragua y Guatemala.
\end{abstract}

Palabras clave: fundamentalismo, Costa Rica, neopentecostalismo, derechos humanos, Estado laico. 


\begin{abstract}
In order to contribute to the discussion on the second electoral round in February 2018 in Costa Rica, this article goes to politics theorists such as Norbert Lechner, Ernesto Laclau y Chantal Mouffe. This aims to explain why the establishment of unshakable truths in political life undermines the dynamics of politics. But at the same time proposes to place in the theoretical analysis the political game that put in motion contradictory cultural dynamics that feeds the political subjectivities. Reflect on the risks that currently run the significant triumphs of movements around sexuality before the onslaught of religious fundamentalism to the culture of tolerance. The article also proposes to locate the Costa Rican case in dynamics of what we could call cultural globalization that today tends to contempt the agenda that has been built around human rights since the Second World War. Finally, it offers comparative insights with Nicaragua and Guatemala.
\end{abstract}

Keywords: fundamentalism, Costa Rica, neopentecostalism, human rights, lay State.

La aparición del fundamentalismo neopentecostal en la política costarricense data por lo menos de inicios del presente siglo. No obstante, en las pasadas elecciones, se manifestó con toda su crudeza el peligro de su presencia en la política para la vida democrática. Tanto la cultura religiosa como su institucionalidad han ocupado espacios significativos en la esfera pública, desde que Costa Rica asumió la ruta de la democracia representativa. Sin embargo, el extremismo del fundamentalismo neopentecostal, su lenguaje virulento en contra de quienes no asumen sus preceptos morales, su asombrosa capacidad de expansión entre sectores populares e incluso capas medias, su habilidad para acumular inmensos recursos económicos, establecer productivos vínculos con organizaciones similares ubicadas en otros países y, finalmente, atraer a políticos de izquierda y de derecha, ofreciendo los votos de sus obedientes cientos de miles de fieles, hacen evidente que estamos ante un fenómeno religioso con potencialidades inéditas. En la actualidad, el neopentecostalismo tiene una fuerte presencia en otros países de América Latina. El Frente Sandinista de Liberación Nacional (FSLN) en Nicaragua es un caso emblemático de una izquierda reciclada, que se ha apropiado de la institucionalidad gracias a la convivencia de líderes religiosos católicos y neopentecostales. Las derechas en el poder en Brasil y Guatemala cuentan con el apoyo masivo del neopentecostalismo y, trascendiendo nuestro continente, gobiernos comandados en Rusia por Vladimir Putin y en Turquía por Recep Tayyip Erdogan han obtenido muy buenos réditos de la alianza con el poder religioso. 
Pero este auge del fundamentalismo religioso en diversas regiones del planeta se explica, en buena medida, por transformaciones acaecidas en el proyecto neoliberal. Si bien en décadas previas este ofreció un rostro amable a la diversidad cultural, a las demandas de las mujeres y de las comunidades LGBTI, en la actualidad esta apertura tiende a desaparecer. El antropólogo Charles Hale hablaba, en los noventa, del "multiculturalismo neoliberal" (Hale, 2008, p. 16). En la época actual, el presidente de Estados Unidos, Donald Trump, acuerpado por conservadores religiosos representantes de grandes capitales, desafía la compleja y difícil construcción, a partir de la Segunda Guerra Mundial, de un marco de respeto a la diversidad social en el ámbito de la política y de los organismos internacionales. El poderoso fundamentalismo estadounidense se encuentra bien adobado con el prejuicio racial, la homofobia y el sexismo, los cuales se alimentan de una violencia discursiva que creíamos había sido erradicada de la esfera pública.

En nuestro país tenemos años de lidiar con personajes como Justo Orozco, quien irónicamente tuvo a su cargo la presidencia de la Comisión Legislativa de Derechos Humanos de la Asamblea Legislativa. ${ }^{1}$ Pero, para entonces, realmente teníamos el convencimiento de que su actuación en contra de los derechos de las minorías sexuales había sido ampliamente rechazada por las mayorías del país. Sin embargo, en el 2018, un personaje con atributos similares tuvo altas posibilidades de convertirse en presidente de la República. La irresponsabilidad del Partido Liberación Nacional (PLN) y, en los últimos tiempos, de la Iglesia católica ha venido cimentando el camino para afirmar su presencia en el poder del Estado costarricense. En este proyecto, excelsas instituciones del país, como el Tribunal Supremo de Elecciones (TSE), violentando el orden constitucional, han avalado la inscripción de partidos religiosos, en cuenta, por supuesto, el que lidera Fabricio Alvarado: el Partido Restauración Nacional (PRN). En las últimas elecciones, los ciudadanos pudimos apreciar los resultados de la alianza que se ha venido tejiendo entre el PLN y los neopentecostales. Los integrantes del PLN creyeron que el PRN se mantendría como partido minoritario, el cual podría manipularse en su beneficio, siempre que se les complaciera en los temas de su interés: dar marcha atrás en el avance de los derechos de la mujer y de las minorías sexuales. Sin embargo, en la primera ronda electoral

$1 \mathrm{Al}$ respecto, puede consultarse La Nación, 26/2/2013. 
del presente año, el PLN recibió la sorpresa de que el PRN había quedado en primer lugar, mientras que el primero, ocupando un tercer lugar, quedó excluido de la segunda ronda.

Un grupo significativo de ciudadanos, sobre todo en la primera ronda electoral, optó por votar por el PRN en respuesta a una atmósfera de pánico generada ante medidas tomadas por el Gobierno, así como alimentada por buena parte de los medios de comunicación y las iglesias. La implementación de las Guías de la Afectividad y la Sexualidad en las escuelas y colegios tuvo como respuesta la convocatoria, por parte de líderes de la iglesia católica y de las iglesias neopentecostales, a la marcha contra la supuesta "ideología de género" (Marcha por la familia). Pocos días antes de las elecciones, al conocerse el resultado de la consulta sobre el matrimonio igualitario a la Corte Interamericana de Derechos Humanos, el revuelo conservador alcanzó su clímax.

Intuimos que buena parte de los ciudadanos le dio el voto al PRN creyendo que este afectaría solamente los derechos de las mujeres y los homosexuales, el resto de la institucionalidad funcionaría como lo había hecho hasta entonces. Por otra parte, hubo quienes estuvieron dispuestos a sacrificar derechos humanos por la promesa de un mejoramiento sustancial de la economía, a partir de la profundización de las políticas neoliberales. No obstante, el problema del neopentecostalismo, así como de otros fundamentalismos que han venido posicionándose en la esfera política en distintos países del continente americano y del europeo, va mucho más allá. Amenaza con socavar los fundamentos mismos de la institucionalidad democrática. Se equivocan quienes, en espera de supuestos réditos económicos, deciden apoyar la desestabilización e incluso la destrucción de instituciones que protegen derechos de grupos específicos, pensando que esa pérdida de derechos no les afecta directamente. A fin de cuentas, el derrumbe de la institucionalidad no solo se quedará en esos espacios del odio, sino que esa capacidad de quienes ostentan el poder de ejercer violencia sobre la alteridad interna, de clausurar espacios de la vida política, tendrá efectos en las más diversas dimensiones de la vida social.

En las siguientes líneas, acudimos a teóricos de la política como Norbert Lechner, Ernesto Laclau y Chantal Mouffe, para explicar por qué la 
instauración de verdades inconmovibles en la esfera pública atenta directamente contra las dinámicas propias de lo político.

Según Norbert Lechner (1983), el consenso, objetivo fundamental de la vida política, es indispensable para poner en un juego interactivo las fuerzas sociales que se enfrentan en la arena pública. Pero, en realidad, el consenso es una utopía. Su realización plena acabaría con las dinámicas propias de la vida política, dando paso al autoritarismo. Esto significa que el espacio de lo político no puede estar regido por un discurso fijo, intocable, sacralizado, pues se trata de un espacio de convergencia de distintas voces que responden a un orden instituido, pero que, a la vez, en ese proceso de negociación permanente, lo transforman. En un intercambio dialógico, de acuerdo con el concepto creado por Mijail Bajtin, esas voces que convergen también van moldeando las subjetividades de los interlocutores y, por supuesto, del mundo social en el que participa de la ciudadanía (Hernández, 2011). Es decir, no salimos incólumes de ese intercambio. La participación, por muy distintas vías en la arena política, nos va transformando. En el imaginario de los setenta, una manifestación gay convocaba a la risa, nos remitía al travestismo carnavalesco, que desde la época colonial divirtió recurrentemente al público durante los festejos. Hoy, en cambio, hemos naturalizado que la población LGBTI ocupe el terreno de lo público, en demanda de derechos que específicamente le competen. Es decir, es evidente que su presencia en el espacio público ha permeado nuestra subjetividad. No obstante, este pequeño pero significativo triunfo de los movimientos en torno a la sexualidad puede perderse rápidamente, ante la embestida del conservadurismo religioso a la cultura de tolerancia.

La dinámica de lo político transforma nuestras prácticas e imaginarios discursivos. Laclau y Mouffe, en Hacia la radicalización de la democracia, refieren a la construcción de cadenas de equivalencia, anclajes provisorios que permiten la construcción de alianzas. Pero estas últimas no se reducen a pactos para alcanzar fines políticos determinados. Mutan el horizonte de lo político, el cual, en los términos de Laclau y Mouffe, es producto de la construcción histórica, de la voluntad de cimentar un conjunto de referentes a partir de los cuales se desarrolla la arena política. Estos referentes, lejos de estar escritos en piedra, van siendo transformados en el proceso político mismo (Gasché, 1984). 
Sin embargo, considero que no podemos ver esa identidad política aislada del resto de las dimensiones de la subjetividad. Por esa razón, los procesos de construcción de equivalencias no están a salvo de contradicciones, ambivalencias, retrocesos. El análisis histórico demanda tomar en cuenta la interacción de los nuevos imaginarios con aquellos previamente instituidos e incorporados en la subjetividad (Castro-Gómez, 2015).

Por otra parte, la contingencia en lo político tiene diferentes niveles. Digámoslo así: hay núcleos fuertes, por los que se han sedimentado en la subjetividad ciudadana principios, valores y visiones de mundo. Existe un orden instituido, conformado por instituciones, leyes, discursos y prácticas políticas, el cual es universal, en el sentido de que es el lugar donde se lleva a cabo la interacción de las distintas voces que conforman el espacio público.

Hay una especie de "núcleos duros" en la identidad que, por supuesto, pueden ser desafiados, pero no dejan de estar latentes en las subjetividades construidas, a partir de prácticas discursivas y performativas que se reproducen en la vida cotidiana. Los imaginarios religiosos, así como imaginarios que devienen de prácticas recurrentes en la arena pública, se introyectan y, en alguna forma, se sedimentan en la identidad (Gómez, 2015). En la lucha política, es posible desafiarlos y, en este proceso, las personas pueden convivir con perspectivas del mundo que, en alguna medida, son contradictorias (Florez-Estrada, 2011). No obstante, la experiencia vital, que ha sido matizada con otras discursividades o ha quedado, en alguna forma, relegada ante nuevos estímulos discursivos que devienen de la arena pública, puede manifestarse con toda su potencialidad.

Si bien las dinámicas de lo político, como lo apuntan Laclau y Mouffe, van transformando al sujeto, en este proceso se consolida una institucionalidad que marca el terreno en el que tiene lugar el enfrentamiento de las fuerzas sociales. La ampliación, en los últimos tiempos, de ese "marco referencial", fundado en los derechos humanos, está siendo fuertemente desafiado por el fundamentalismo. Este ha sabido potenciar valores conservadores, con base en una cultura religiosa que hasta hoy ha convivido, aunque no sin contradicciones, con ese otro núcleo duro que se constituye alrededor de los derechos humanos.

Ese espacio universal de la política que, de acuerdo con la obra La radicalización de la democracia, no deviene de una exterioridad previamente 
constituida, va moldeando, le va dando cuerpo al teatro en el que se desarrolla la vida pública. El poder de ese centro hegemónico, en términos gramscianos, se logra a partir de la construcción de un sentido común que llega a ser representativo de la colectividad. Ese andamiaje que da sentido al accionar político también es objeto de remodelación, a partir de las disputas que operan en su interior.

Si bien, esos núcleos fuertes, constituidos por valores e instituciones que conforman la universalidad en la que se desarrolla el sistema político, pueden ser enriquecidos, reinterpretados, alimentados con nuevas perspectivas del mundo social, se mantienen como anclajes donde se ubica el sentido común. Ese andamiaje, que contiene los espacios donde se desarrolla lo político, se va alimentando y reconfigurando, pero posee ejes centrales, medulares, que trascienden los gobiernos mismos, aunque estos provengan de distintas tendencias ideológicas. Su desafío frontal puede anunciar el derrumbe de un sistema hegemónico.

Creo que en la coyuntura electoral el país presenció el desafío a uno de los baluartes del sistema político: los derechos humanos, pues, muy a tono con las tendencias globales, un conjunto importante de la sociedad civil se estaba desconectando de dicho anclaje. El Estado ha venido perdiendo terreno frente al poder de los pastores y de grupos católicos conservadores. En los neopentecostalismos y en el conservadurismo católico, los derechos humanos se transforman en discursividad ajena al sentido común imperante en un número considerable de costarricenses. Por ejemplo, los derechos más convencionales del Estado democrático, como la libre expresión, la libertad de conciencia, han perdido capacidad de convocatoria en estos sectores. Para ellos, la universalidad ideal es de orden religioso. La semiosfera es un concepto creado por Iuri Lotman para el estudio de los campos semióticos, espacios sociales donde se desarrolla una discursividad integrada por una serie de símbolos conectados entre sí, que permiten al ser humano ubicarse y actuar en el mundo en el cual convive. En esas producciones de sentido, desde la vigorosa y agresiva imposición dogmática, se cierran los espacios para colocar temas como los derechos y garantías de los seres humanos. Un sistema hegemónico no es sustituido por otro, pues, más bien, ese campo de fuerzas que dinamiza lo político se petrifica y pierde la flexibilidad requerida para que opere el intercambio dialógico. 
Nos advierte Lechner que cuando ese lugar de lo político es completamente saturado por un discurso determinando, aun cuando este pueda ser avalado por las mayorías, hemos dado el paso hacia el autoritarismo. Entonces, las dinámicas que renuevan la vida política se cristalizan. Cualquier discurso que pretenda introducir cambios se enfrenta con una muralla inaccesible. Podemos seguir hablando de elecciones "limpias", pero ello no impide que se imponga el autoritarismo. De todas formas, es una falacia esa concepción de que la democracia es simplemente el poder de las mayorías. Esta es una razón muy poderosa para defender el Estado laico, el cual es una de las pocas garantías de sobrevivencia de la vitalidad discursiva que inyecta de energía la dimensión de lo político. Cuando las verdades absolutas se posesionan del espacio público y lo reducen a su mínima expresión, esa interacción discursiva que genera la búsqueda del consenso ya no es ni siquiera necesaria para mantener el poder. Esto se juega en otros términos. Posiblemente, podríamos llegar a hablar de "paternalismo neopentecostal" como concepto que sustituye al Estado benefactor. Ya estamos presenciando cómo los magros beneficios para pobres se reparten en las iglesias. Una vez que estas se posesionan de espacios políticos, su capacidad distributiva garantiza el incremento de las redes clientelares que fundamentan su permanencia en el poder, ya sea a partir de sus propios representantes o bien por interpósita mano.

En Nicaragua, ante la violenta pérdida de la hegemonía del gobierno Ortega-Murillo, el poder religioso, en particular católico, asume una posición de liderazgo frente al movimiento cívico que busca su derrocamiento. Sin embargo, ha sido a todas luces evidente que la jerarquía católica y las iglesias neopentecostales han constituido baluartes fundamentales sobre los que, en dicho país, el poder omnímodo se fue cincelando hasta cerrar los posibles espacios de disidencia dentro del Estado.

El FSLN encontró estrategias eficaces para mantenerse en el poder indefinidamente. En la actualidad, las masivas protestas en contra de la pareja gobernante se estrellan contra un poder blindado. Ortega expulsó del campo político a sus competidores, se garantizó la lealtad absoluta de sus funcionarios públicos y del sistema represivo, así como negoció con las iglesias clausurando toda vía reivindicativa del feminismo y de las minorías sexuales. "Bendecidos, prosperados y en victorias", lema de la pareja gobernante y copia 
textual de una de las expresiones características del neopentecostalismo, cubría hasta muy recientemente la geografía del país. Esta presencia de las iglesias en el poder no solo ha clausurado espacios de las luchas feministas y de la población LGBTI. El Gobierno ha logrado manipular las instituciones públicas para acabar literalmente con la oposición.

En Guatemala la alianza de los militares con los neopentecostales data por lo menos de inicios de los ochenta. A la frágil institucionalidad de este país le corresponde una débil sociedad civil. Pero eso sí, la fuerza del neopentecostalismo asegura excelentes réditos, una vez que se negocia con su liderazgo. Si bien los neopentecostales, por restricciones constitucionales, no pueden constituir su propio partido político, la realidad es que resulta casi imposible ganar una elección sin el apoyo de los poderosos pastores.

Las experiencias de otros países como Nicaragua y Guatemala no nos son del todo ajenas. Tuvimos a Justo Orozco, irónicamente, como presidente de la comisión legislativa de derechos humanos en el gobierno de Laura Chinchilla. Álvarez de Santi, como candidato electo del PLN, entregó el control de la Asamblea Legislativa a la fracción neopentecostal. Sin embargo, la experiencia de un gobierno que es producto de un partido pentecostal es algo inédito. Me temo que, si esto ocurre, ello potenciará la destrucción de las instituciones democráticas en un país que, en relación con sus vecinos, ha avanzado sustancialmente en este campo y, por ello, tiene mucho que perder. Costa Rica, durante el siglo XX, ha vivido acontecimientos históricos en los que los avances en los derechos de las mujeres han tenido como respuesta virulentas reacciones conservadoras. Pero esto es diferente. No estamos en la misma situación de mediados del siglo XX. Vivimos la amenaza de que una institucionalidad construida a partir de las luchas por expandir el concepto de democracia sea desmontada. Recordemos que toda conquista política es precaria. Por tanto, violentamente puede perderse el inmenso esfuerzo de mujeres y hombres comprometidos en la lucha contra las asimetrías de género y en la dignificación de la vida de todas y todos, independientemente de su orientación social, esfuerzos que se concretizan no solo en leyes, en instituciones, sino, fundamentalmente, en relaciones humanas, en experiencias vitales.

Entre los meses de febrero y marzo de 2018, se constituyó una impresionante alianza cívica que logró enfrentar exitosamente al fundamentalismo 
religioso y sus aliados. Sin embargo, estos ya cuentan con importantes espacios de poder en el seno del Estado y, como lo experimentamos en esta última elección, vendrán nuevas coyunturas en las que diversos temas de carácter moral, económico, migratorio, entre otros, podrían ofrecer un buen terreno para que el conservadurismo religioso, a tono con el contexto internacional, se posesione con firmeza en el campo electoral.

De repente, es posible que quienes nos sentimos parte del mundo correcto, del orden establecido, empecemos a percibir que tampoco estamos ajenos al ojo vigilante del orden divino. ¿Nos invadirá entonces un sentimiento de anomia, de extrañamiento en nuestro propio país? La historia contemporánea de América Latina nos muestra que el mejor antídoto para luchar contra los desafíos del autoritarismo se encuentra en la construcción de sujetos ciudadanos autónomos, capaces de tomar sus propias decisiones sin depender de las migajas o la protección de instituciones religiosas o estatales.

\section{Referencias bibliográficas}

Castro-Gómez, S. (2015). Revolución sin sujeto. Slavoj Zizek y la crítica del historicismo posmoderno. México, D. F.: AKal/InterPares.

Florez-Estrada Pimentel, M. (2011). De "ama de casa" a mulier economicus. Sexo, género, subjetividad y economía en Costa Rica Contemporánea. San José: Editorial UCR.

Gasché, R. (1984). ¿Qué tan vacío puede estar el vacío? En S. Critchley y O. Marchart (Comp.), Laclau. Aproximaciones críticas a su obra (pp. 33-53). México, D. F.: Fondo de Cultura Económica.

Gómez, J. P. (2015). Autoridad/Cuerpo/Nación. Batallas culturales en Nicaragua (1930-1943). Managua: IHNCA-UCA.

Hale, Ch. (2008). Neoliberal Multiculturalismo. Political and Legal Anthropology Review, 28(1), 10-28, 36-51. https://doi.org/10.1525/pol.2005.28.1.10

Hernández-Silvestre. M. (2011). Dialogismo y alteridad en Bajtín. Coatepec, 21, 11-32.

Laclau, E. y Mouffe, Ch. (1987). Hegemonía y estrategia socialista. Hacia una radicalización de la democracia. Madrid: Siglo XXI.

Lechner, N. (1983). El consenso como estrategia y como utopía. Zona Abierta, 29, 1-28.

Lotman, I. M. (1996). La semiosfera I. Semiótica de la cultura y del texto. Madrid: Ediciones Cátedra, S. A.

S. A. (2017). Marcha por lafamilia reúnea miles en contra dela ideología de género. Oncenoticias. Recuperado de http://www.oncenoticias.cr/marcha-la-familia-reune-miles-ideologia-genero/

Sequeira, A. (2013). Diputados piden a Justo Orozco dejar comisión. La Nación. Recuperado de https://www.nacion.com/el-pais/politica/diputados-piden-a-justo-orozco-dejar-comision/ OI6NRJJA3BFBLJQIUTDJWL2V4E/story/ 